\title{
Disentangling the Factors Driving Users' Continuance Intention towards Social Media \\ A Configurational Perspective
}

Li, Hongxiu; Li, Lirui; Gan, Chunmei; Liu, Yong; Tan, Chee-Wee; Deng, Zhonghua

Document Version

Accepted author manuscript

Published in:

Computers in Human Behavior

DOI:

10.1016/j.chb.2018.03.048

Publication date:

2018

License

CC BY-NC-ND

Citation for published version (APA):

Li, H., Li, L., Gan, C., Liu, Y., Tan, C-W., \& Deng, Z. (2018). Disentangling the Factors Driving Users'

Continuance Intention towards Social Media: A Configurational Perspective. Computers in Human Behavior, 85, 175-182. https://doi.org/10.1016/j.chb.2018.03.048

Link to publication in CBS Research Portal

\section{General rights}

Copyright and moral rights for the publications made accessible in the public portal are retained by the authors and/or other copyright owners and it is a condition of accessing publications that users recognise and abide by the legal requirements associated with these rights.

\section{Take down policy}

If you believe that this document breaches copyright please contact us (research.lib@cbs.dk) providing details, and we will remove access to the work immediately and investigate your claim.

Download date: 26. Apr. 2023
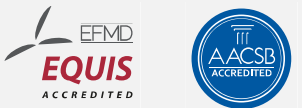


\section{Disentangling the Factors Driving Users' Continuance Intention towards Social Media: A Configurational Perspective}

\section{Hongxiu Li, Lirui Li, Chunmei Gan, Yong Liu, Chee-Wee Tan, and Zhonghua Deng}

Journal article (Accepted manuscript*

\section{Please cite this article as:}

Li, H., Li, L., Gan, C., Liu, Y., Tan, C-W., \& Deng, Z. (2018). Disentangling the Factors Driving Users' Continuance Intention towards Social Media: A Configurational Perspective. Computers in Human Behavior, 85, 175-182. D0l: 10.1016/j.chb.2018.03.048

\section{DOl: 10.1016/j.chb.2018.03.048}

* This version of the article has been accepted for publication and undergone full peer review but has not been through the copyediting, typesetting, pagination and proofreading process, which may lead to differences between this version and the publisher's final version AKA Version of Record.

(C) 2019. This manuscript version is made available under the CC-BY-NC-ND 4.0 license http://creativecommons.org/licenses/by-nc-nd/4.0/ 


\section{Disentangling the Factors Driving Users' Continuance Intention Towards Social Media: A Configurational Perspective}

Hongxiu Li, (corresponding author) post doctoral researcher, Department of Management and Entrepreneurship, Turku School of Economics, University of Turku, Turku, Finland, hongxiu.li@utu.fi

Lirui Li, School of Computer and Information Science, Southwest University, Chongqing, China, liruili1989@gmail.com

Chunmei Gan, School of Information Management, Sun Yat-sen University, Guangzhou, Chinachunmei_gan@163.com

Yong Liu, assistant professor, Department of Information and Service Economy, Aalto University School of Business, Helsinki, Finland, yong.liu@aalto.fi

Chee-Wee Tan, professor, Department of IT Management, Copenhagen Business School, Copenhagen, Denmark, cta.itm@cbs.dk

Zhonghua Deng, Professor, Information School, Wuhan University, Wuhan, China, hellowdzh@126.com 


\section{Disentangling the Factors Driving Users' Continuance Intention Towards Social Media: A Configurational Perspective}

Abstract: Building on perceived value theory, this study employs fuzzy set Qualitative Comparative Analysis (fsQCA) to derive configurational models that embody causal conditions for predicting users' continuance intention towards social media. From reviewing extant literature, we advanced four value dimensions to be gained from social media usage, namely hedonic value (enjoyment), information value (information documentation and information sharing), media value (media appeal), and social value (social interaction), which are measured via a survey questionnaire. Our findings reveal seven distinct configurations of causal conditions for inducing continuance intention towards social media among Chinese users. Particularly, the frequency of social media usage combined with perceptions of enjoyment were found to be core conditions reinforcing users' continuance intention towards social media. In turn, the existence of multiple configurations implies that social media service providers could concurrently pursue differentiated strategies for retaining users.

Keywords: Continuance intention, social media, fuzzy set Qualitative Comparative Analysis (fsQCA), configuration

\section{INTRODUCTION}

In recent years, social media, in the likes of Facebook, LinkedIn, Flickr, and Twitter, have permeated people's lives. People are spending more time on social media, updating their status, sharing pictures, videos, and knowledge, as well as posting comments and participating in communal activities (Zhang et al. 2017). Due to intense competition among social media service providers, users enjoy the luxury of having multiple platforms to choose from and can readily switch among them. According to a report by PewResearch (2015), users' participation on several prominent social media platforms, such as Instagram and Pinterest, has stagnated or even declined due to market competition. In this sense, continued usage by intended users is critical for the survival and longevity of social media platforms. Bhattacherjee (2001) posited that the continued usage of an Information System (IS) is vital to its market success because the benefits to be gained from any IS investment can only be realized when the system is subjected to continuous use by its target audience. Consequently, deciphering the motivations driving the continued usage of social media has attracted substantive attention among researchers within the IS field.

A majority of past studies on the continued usage of social media employ predominant statistical techniques, such as Multiple Regression Analysis (MRA) and Structural Equation Modeling (SEM), for analysis. Such techniques typically assume symmetrical relationships between predictors (e.g., motivators) and outcomes (e.g., continued usage of social media) so that each predictor is expected to exert a distinct effect on the outcome of interest. 
Despite the popularity of statistical techniques, they may not be adequate in explaining complex interaction effects among multiple predictors that could influence the continued usage of social media by users (Liu et al. 2014, Ragin, 2000; Park \& El Sawy, 2012; Woodside, 2013). As alleged by Liu et al. (2017), there are multiple sufficient conditions that could jointly predict whether users are likely to continue using an IS, and that these conditions cannot be modeled by conventional regression techniques that are founded primarily on linear relationships. A primary contention of Liu et al. (2017) is that relationships between predictors and system usage behaviors could also be asymmetric, which in turn lends credibility to configurational techniques, such as Fuzzy-Set Qualitative Comparative Analysis (fsQCA), as an alternative approach for exploring IS user behavior.

According to configuration theories, combinations of discrete conditions can lead to the same outcome: the relationships between predictors and outcomes tend to be asymmetric rather than symmetric (Liu et al. 2014, Ragin, 2000; Park \& El Sawy, 2012; Woodside, 2013). Venkatesh et al. (2003) argued that users' decision to continue using an IS is shaped by their perceptions of system attributes, which stem from previous usage experience. Users, after initial usage, may decide to not continue using an IS if only a few conditions are met. In other words, fulfillment of a single condition (no matter how crucial) may not necessarily culminate in users' intention to continue using an IS. For this reason, it is apparent that conventional regression techniques are a mismatch with asymmetrical relationships.

By applying fsQCA, this study attempts to gain an in-depth appreciation of the configuration of conditions that culminate in users' continuance intention towards social media. Furthermore, this study subscribes to the perceived value theory as our theoretical lens for deriving constituent dimensions of perceived value. Specifically, fsQCA is employed to scrutinize the asymmetric relationships between perceived value and users' continuance intention towards WeChat, a popular social media platform in China. Based on a recent report by Tencent, the population of WeChat had ballooned 762 million by the end of March 2016 (Tencent, 2016). Though the user base of WeChat is huge, it also faces intense competition from other market players, such as AliWangWang and Momo, which offer similar services in China.

Our application of fsQCA in IS continuance research is aimed at eliciting multiple causal models that can explain and predict users' continuance intention to use social media. In this sense, fsQCA might offer an alternate avenue for disentangling causal relationships between the antecedents and the outcome of IS continuance by taking into account interdependencies among the former. Having said that, this research does not dismiss the validity and utility of conventional statistical techniques because it is due to the solid foundation provided by past studies on IS continuance that we can embark on a reinterpretation of previous work from a configurational standpoint. 
The remainder of the paper is structured as follows. In Section 2, we conduct a review of extant literature on both IS continuance and perceived value theory. Next, we introduce the fsQCA method in Section 3. In Section 4, we describe our methodological procedures for data collection and analysis as well as present the results from our empirical inquiry. In Section 5, we discuss and highlight the implications of our findings for theory and practice before concluding with the limitations of our study as well as opportunities for future research.

\section{THEORETICAL FOUNDATION}

\subsection{Antecedents of Continuance Intention to Utilize Social Media}

IS continuance is a behavioral outcome that can only manifest after the adoption of an IS, entailing both continuance intention and continued usage of the system. Consequently, IS continuance can be conceived as a form of post-adoption behavior. IS continuance has been a hot topic in the field with prior research giving rise to diverse theories for explaining and predicting IS continuance behavior based on SEM. These theories include the Technology Acceptance Model (TAM) (Davis 1989), IS Success Model (DeLone \& McLean, 1992), Expectation-Confirmation Theory (ECT) (Bhattacherjee, 2001), Theory of Reasoned Action (TRA) (Fishbein \& Ajzen 1975), Flow Theory (Csikszentmihalyi \& LeFevre, 1989), Unified Theory of Acceptance and Use of Technology (UTAUT) (Venkatesh et al. 2003), Use and Gratification (U \& G) Theory (Katz et al., 1974; Weibull, 1985) and Perceived Value (Zeithaml, 1988).

Individuals' continued usage of social media stems from an inherent desire to satisfy their personal needs for enjoyment, information sharing, social interaction, social network expansion, and social presence, or is rooted in their personal characteristics, technology affordance or the perceived utility of social media. Past studies have supplied empirical evidence alluding to distinct motivators for individuals to continue using social media across separate contexts, such as Facebook (Hsu, Tien, Lin, \& Chang, 2015), Snapachat (Jeong \& Lee, 2017; Punyanunt-Carter, De La Cruz, \& Wrench, 2017), Twitter (Lee \& Kim 2014), Microblog (Li, Guo, \& Bai, 2017), social network games (Li et al. 2015), social networking sites (Bae, 2018; Lin, Featherman, \& Sarker, 2017), and virtual worlds (Gallego, Bueno, \& Noyes, 2016). Hsu et al. (2015) discovered that entertainment, information seeking, selfpresentation, and socialization affect individuals' intention to continue using Facebook. Lee and Kim (2014) found that affiliative tendency and communication competence affect Twitter use whereas a desire for network expansion motivates users to both generate tweets and engage in retweeting while surveillance governs the size of the Twitter network. Li et al. (2015) documented three types of gratifications that motivate individuals to continue playing social network games, including hedonic gratification (i.e., enjoyment, fantasy, and escapism), utilitarian gratification (i.e., achievement), and social gratification (i.e., social interaction and 
social presence). Zhang et al. (2017) reported that both hedonic and social value influence the continuance intention of WeChat users. By investigating the effect of the discrepancy between sought and obtained gratification on user satisfaction and continuance intention in the context of social networking sites, Bae (2018) not only revealed disparities between obtained and sought gratification to have a significant impact on user satisfaction and intention to continue using such sites, but he also uncovered habit to have a moderating influence on the preceding relationships. Synthesizing ECT with social networking attributes (i.e., community identification, enjoyment, privacy risk, and reputation), Lin et al. (2017) confirmed that social networking attributes drive users' continuance intention towards social networking sites directly and indirectly via user satisfaction with gender acting as a moderator.

\subsection{Perceived Value in Social Media Usage}

The concept of perceived value has been extensively applied by scholars to explore IS continuance. Originating as a means for defining business issues in marketing research in the 90s, the concept of perceived value has since gained traction in both academic research and industrial practice. Yet, despite its broad application, there is a lack of consensus on the conception of perceived value. Whereas Zeithaml (1988) conceived perceived value as an overall assessment of a product/service by users, Lee et al. (2014) maintained that perceived value is much more sophisticated in nature and should be theorized as a multi-dimensional notion. Within extant IS literature, a handful of studies have decomposed the dimensions of perceived value in IS usage from the viewpoint of motivation theory, delineating between hedonic and utilitarian values as drivers of system usage (Park \& Park, 2009). More recent studies, through investigating IS use across diverse contexts, have further expanded on the dimensionality of perceived value to incorporate elements of emotional value, information value, process value, social value, transaction value, and technology value (Dhir, Khalil, Lonka, \& Tsai, 2017; Gan \& Li, 2018; Lee et al. 2014; Li, Guo, \& Bai, 2017).

In line with advances in the theorization of perceived value, a multitude of studies have researched social media usage from the value perspective. As contended by Lee et al. (2014), perceived value resonates with other behavioral theories like the TRA (Fishbein \& Ajzen 1975) and can shed light on IS use behavior. Because individuals' continuance intention towards social media is a cognitive decision process, they further stated that perceived value, as a context-specific perception, could affect user attitudes and behaviors (Lee et al. 2014). Indeed, prior research has attested to the effect of perceived value on users' continuance intention towards social media. Treating perceived value as a single dimensional concept, AlDebei et al. (2013) discovered perceived value to be a core determinant of users' continuance intention towards Facebook. Conversely, there are also researchers who construe perceived value as a multi-dimensional concept. Lee et al. (2014) distinguished among experiential, 
information, social, and transaction values in their research on Facebook usage. In the same vein, Zhang et al. (2017) connected continuance intention to value consideration by not only delineating perceived value into four distinctive dimensions (i.e., emotional value, hedonic value, information value, and social value), but also uncovering that only hedonic and social values are influential in driving individuals' intention to continue using WeChat. Examining the reason behind individuals' adoption of social networking sites from the perspective of U\&G theory and social influence processes, Ifinedo (2016) revealed that the values of entertainment, self-discovery, and social enhancement, as well as the need to maintain interpersonal connectivity, in conjunction with the social influence process of internalization and identification, shape users' continued usage of social networking sites. Likewise, Gan and Li's (2018) work on social media suggests that hedonic, social, technology, and utilitarian gratifications constitute key motivators driving individuals' intention to continue use WeChat. Specifically, Gan and Li (2018) found that technology gratification (media appeal) exerts the strongest effect on users' continuance intention towards WeChat, followed by hedonic gratification (perceived enjoyment) and utilitarian gratification (information sharing).

Building on prior research, this study delineates the perceived value of social media usage into four dimensions: hedonic value (enjoyment), information value (information documentation and information sharing), media value (media appeal), and social value (social interaction). Of the four dimensions, hedonic value refers to the enjoyment, fun and excitement users can obtain on social media from interacting with peers, participating in entertaining activities, and perusing content (Zhang et al. 2017). Within IS literature, there is an abundance of studies equating perceived enjoyment with hedonic value in social media usage (Li et al. 2015; Ng, 2016; Sharma et al. 2016). Adhering to past studies, we hence posit perceived enjoyment to be representative of hedonic value in social media usage.

In contrast, information value refers to the benefits of acquiring useful information from social media usage. Such useful information could include curation of key events in individuals' daily lives through social media postings and/or insights gleaned from shared information by peers (Zhang et al. 2017). Similarly, we regard information documentation and sharing to be focal constituents of information value in social media usage.

Conversely, media value refers to users' perceptions of how easy and convenient it is for them to communicate with others via the modalities afforded by social media (James et al., 1995). In this study, we propose to capture media value in social media usage through the notion of media appeal because it reflects the extent to which the underlying functionalities are supportive of social media as a communication channel.

Last but not least, social value denotes the benefits to be gained from interacting with others via social media. These benefits could take the form of building and sustaining relationships, representing themselves effectively, as well as soliciting social endorsement 
and support (Li. et al. 2015; Lin, 2011; Zhang et al. 2017). We thus postulate that social value in social media usage should encapsulate social interactions among users.

\section{FUZZY SET QUALITATIVE COMPARATIVE ANALYSIS (fSQCA)}

Developed by Ragin (1987), fsQCA rests on the premise that combinations of distinct causal conditions (as configurations), rather than any singular cause with its own isolated effect, are deterministic of an outcome of interest (Fiss, 2011; Ragin, 2000). In contrast to variance-based approaches in which multiple variables (or causal conditions) will compete in explaining an outcome of interest (Woodside, 2013), fsQCA enables analysis of interdependencies among variables by acknowledging that variables could be combined to form configurations in realizing the outcome. Consequently, fsQCA, as a set-based approach, offers an appropriate means for accommodating complex complementarities and non-linear relationships among multiple variables (e.g., antecedents, causal conditions and stimuli) that jointly constitute an outcome of interest.

Additionally, fsQCA caters for separate combinations of casual conditions, which could lead to an identical outcome (Berg-Schlosser et al. 2009). This means that fsQCA, in contrast to conventional statistical techniques which are concerned with the net impact of an independent variable on an outcome of interest but ignore interdependencies among these variables, can elicit multiple configurations for which each is sufficient in producing the same outcome of interest (Ragin, 2000, 2008a, 2008b). Furthermore, by examining the asymmetric relationships among variables, fsQCA can illuminate both the presence and absence of causal conditions that are necessary for an outcome of interest to emerge (Woodside 2010a, 2010b).

\section{RESEARCH METHODOLOGY}

\subsection{Measurement Development}

Consistent with our theory development, six constructs were included in our research model to explore users' continuance intention towards social media, namely information documentation, information sharing, media appeal, social interaction, perceived enjoyment, and continuance intention. Table 1 summarizes the definitions for these six constructs.

Table 1. Definition of Focal Constructs

\begin{tabular}{|l|l|l|l|}
\hline \multicolumn{2}{|c|}{ Construct } & Theoretical Source & \multicolumn{1}{c|}{ Definition } \\
\hline Hedonic Value & $\begin{array}{l}\text { Perceived } \\
\text { Enjoyment }\end{array}$ & $\begin{array}{l}\text { Hedonic Theory; } \\
\text { Motivation Theories }\end{array}$ & $\begin{array}{l}\text { Extent to which using WeChat is perceived } \\
\text { to be enjoyable (Ryan \& Deci, 2000) }\end{array}$ \\
\hline Social Value & $\begin{array}{l}\text { Social } \\
\text { Interaction }\end{array}$ & $\begin{array}{l}\text { Self- Determination } \\
\text { Theory }\end{array}$ & $\begin{array}{l}\text { Extent to which WeChat is utilized as a } \\
\text { social environment to interact with others } \\
\text { (Deci \& Ryan, 2000) }\end{array}$ \\
\hline $\begin{array}{l}\text { Information } \\
\text { Value }\end{array}$ & $\begin{array}{l}\text { Information } \\
\text { Documentation }\end{array}$ & $\begin{array}{l}\text { Information } \\
\text { Processing }\end{array}$ & $\begin{array}{l}\text { Extent to which using WeChat is utilized } \\
\text { to document different events in its users } \\
\text { daily lives (Nardi, Schiano, Gumbrecht, \& } \\
\text { Swartz, 2004) }\end{array}$ \\
\hline
\end{tabular}




\begin{tabular}{|l|l|l|l|}
\hline & $\begin{array}{l}\text { Information } \\
\text { Sharing }\end{array}$ & $\begin{array}{l}\text { Knowledge Sharing } \\
\text { Theory }\end{array}$ & $\begin{array}{l}\text { Extent to which WeChat is utilized to share } \\
\text { information with others (Trammell, } \\
\text { Tarkowski, \& Hofmokl, 2004) }\end{array}$ \\
\hline Technology Value & Media Appeal & $\begin{array}{l}\text { Communication } \\
\text { Theory }\end{array}$ & $\begin{array}{l}\text { Extent to which WeChat is attractive and } \\
\text { enables communication with others in an } \\
\text { easy and immediate way (James et al., } \\
\text { 1995) }\end{array}$ \\
\hline Continuance intention & $\begin{array}{l}\text { ECT-based IS } \\
\text { continuance model }\end{array}$ & $\begin{array}{l}\text { Users' intention to continue using WeChat } \\
\text { (Bhattacherjee 2001). }\end{array}$ \\
\hline
\end{tabular}

All six constructs were measured via multiple items, and each item, in turn, was measured using a seven-point Likert scale, ranging from Strongly Disagree (1) to Strongly Agree (7). The measurement items for perceived enjoyment were adapted from the work of van der Heijden (2003) whereas the measures for information documentation, information sharing, and media appeal were derived from the study by Liu et al. (2016). Items measuring social interaction were elicited from the work of Liu et al. (2016) and Papacharissi (2002). Finally, measures for continuance intention were extracted from Bhattacherjee (2001). All measurement items are displayed in Appendix A.

Based on the measurement items, a survey questionnaire was first developed in English before being inspected by two researchers for content validity. The questionnaire was subsequently translated into Chinese by a researcher who is a native speaker of the language. A pilot study was conducted among a group of 20 university students, who possess extensive usage experience in WeChat, to ascertain the reliability and validity of our survey instrument. No major issue surfaced during the pilot study.

\subsection{Data Collection}

An online survey questionnaire was employed in this study to collect empirical data from WeChat users in China via the snowball sampling method. The questionnaire was delivered via WeChat. We first invited students enrolled in a large tertiary institution in Southern China to answer the questionnaire, and respondents, in turn, were requested to disseminate the online survey to their contacts via WeChat. We utilized the popular Red Packet function on WeChat to offer monetary incentives to respondents. Respondents would be automatically entered into a draw to win a red packet ranging from RMB $\$ 0.10$ to RMD $\$ 5.00$. The data collection lasted for 2 weeks. In total, we received 326 responses, of which only 297 responses were valid. A detailed breakdown of the demographic characteristics of respondents is given in Table 2, and it generally conforms to the demographic composition of WeChat users recently released by Tencent (2016).

Table 2. Demographic Composition of Survey Respondents

\begin{tabular}{|l|l|l|l|}
\hline \multicolumn{2}{|c|}{ Demographic Characteristic } & Frequency & Percentage (\%) \\
\hline Gender & Male & 106 & 35.7 \\
\hline
\end{tabular}




\begin{tabular}{|l|l|l|l|}
\hline \multirow{4}{*}{ Age } & Female & 191 & 64.3 \\
\hline \multirow{4}{*}{$\begin{array}{l}\text { Wuration of } \\
\text { WeChat Usage }\end{array}$} & $17-21$ & 121 & 40.7 \\
\cline { 2 - 4 } & $22-26$ & 64 & 21.5 \\
\cline { 2 - 4 } & $27-31$ & 67 & 22.6 \\
\cline { 2 - 4 } & $32-36$ & 26 & 8.8 \\
\cline { 2 - 4 } & Lesove 36 & 19 & 6.4 \\
\cline { 2 - 4 } & $6-12$ months & 24 & 2.4 \\
\cline { 2 - 4 } & $1-2$ years & 109 & 3.1 \\
\cline { 2 - 4 } & $2-3$ years & 96 & 32.3 \\
\cline { 2 - 4 } & More than 3 years & 61 & 20.5 \\
\hline \multirow{4}{*}{$\begin{array}{l}\text { Frequency of } \\
\text { WeChat Usage }\end{array}$} & Many times a day & 209 & 70.4 \\
\cline { 2 - 4 } & Several times a day & 71 & 23.9 \\
\cline { 2 - 4 } & Once a day & 6 & 2.0 \\
\cline { 2 - 4 } & Less than once a day & 11 & 3.7 \\
\hline
\end{tabular}

\subsection{Measurement Reliability and Validity}

To assess the reliability and validity of the survey instrument, the measurement model was analyzed. Tables 3 and 4 present the results from our analysis of the measurement model. Convergent validity reflects the degree to which the measures underlying a latent constructassumed to be theoretically connected - are in fact connected. Convergent validity can be assessed by estimates of the factor loadings of measurement items as well as the Composite Reliability (CR) and Average Variance Extracted (AVE) for each construct.

Table 3. Construct Reliability and Validity

\begin{tabular}{|c|c|c|c|c|c|c|c|c|c|}
\hline Construct & AVE & CR & $\begin{array}{l}\text { Cronbach's } \\
\text { Alpha }\end{array}$ & CI & ID & IS & MA & PE & SI \\
\hline $\begin{array}{l}\text { Continuance Intention } \\
\text { (CI) }\end{array}$ & 0.859 & 0.948 & 0.918 & 0.927 & & & & & \\
\hline $\begin{array}{l}\text { Information } \\
\text { Documentation (ID) }\end{array}$ & 0.944 & 0.971 & 0.940 & 0.332 & 0.971 & & & & \\
\hline $\begin{array}{l}\text { Information Sharing } \\
\text { (IS) }\end{array}$ & 0.777 & 0.912 & 0.855 & 0.503 & 0.540 & 0.881 & & & \\
\hline Media Appeal (MA) & 0.776 & 0.912 & 0.856 & 0.616 & 0.414 & 0.524 & 0.881 & & \\
\hline $\begin{array}{l}\text { Perceived Enjoyment } \\
\text { (PE) }\end{array}$ & 0.898 & 0.964 & 0.943 & 0.580 & 0.416 & 0.479 & 0.557 & 0.948 & \\
\hline Social Interaction (SI) & 0.804 & 0.925 & 0.878 & 0.484 & 0.420 & 0.513 & 0.473 & 0.468 & 0.897 \\
\hline
\end{tabular}

Results indicate that the factor loadings of all measurement items are above 0.80 . Likewise, the composite reliability scores for all latent constructs are greater than 0.90 , and their AVE values are more than 0.7. Since the values for factor loadings, composite reliability and AVE exceed recommended thresholds of $0.7,0.8$ and 0.5 respectively (see Table 3) 
(Fornell \& Larcker, 1981), we can be assured of convergent validity in this study.

Discriminant validity is assessed by comparing the squared root of the AVE for each latent construct and the cross-loadings for each measurement item. As shown in Table 3, the squared root of the AVE for each latent construct is higher than its correlations with other constructs. Furthermore, we can deduce that each item is reflective of its underlying latent construct because the within-construct loading for an item is higher on its measured construct than its cross-loadings on other constructs (see Table 4). This in turn testifies to the discriminant validity of our study (Chin, 1998; Fornell \& Larcker, 1981).

Table 4. Confirmatory Factor Analysis (CFA)

\begin{tabular}{|c|c|c|c|c|c|c|}
\hline & CI & ID & IS & MA & PE & SI \\
\hline CI1 & 0.936 & 0.339 & 0.490 & 0.699 & 0.544 & 0.491 \\
\hline CI2 & 0.901 & 0.305 & 0.432 & 0.635 & 0.502 & 0.431 \\
\hline CI3 & 0.942 & 0.278 & 0.474 & 0.653 & 0.565 & 0.420 \\
\hline ID2 & 0.315 & 0.970 & 0.516 & 0.410 & 0.403 & 0.415 \\
\hline ID3 & 0.330 & 0.973 & 0.533 & 0.394 & 0.404 & 0.400 \\
\hline IS1 & 0.436 & 0.469 & 0.870 & 0.476 & 0.404 & 0.411 \\
\hline IS2 & 0.465 & 0.462 & 0.926 & 0.440 & 0.423 & 0.482 \\
\hline IS3 & 0.427 & 0.499 & 0.846 & 0.470 & 0.440 & 0.463 \\
\hline MA1 & 0.674 & 0.403 & 0.504 & 0.880 & 0.538 & 0.500 \\
\hline MA2 & 0.635 & 0.327 & 0.426 & 0.899 & 0.451 & 0.365 \\
\hline MA3 & 0.576 & 0.361 & 0.452 & 0.864 & 0.480 & 0.376 \\
\hline PE1 & 0.555 & 0.392 & 0.440 & 0.528 & 0.957 & 0.455 \\
\hline PE2 & 0.553 & 0.380 & 0.444 & 0.520 & 0.960 & 0.470 \\
\hline PE3 & 0.540 & 0.410 & 0.478 & 0.536 & 0.926 & 0.404 \\
\hline SI1 & 0.432 & 0.398 & 0.403 & 0.402 & 0.419 & 0.872 \\
\hline SI2 & 0.395 & 0.394 & 0.461 & 0.417 & 0.398 & 0.903 \\
\hline SI3 & 0.468 & 0.341 & 0.512 & 0.451 & 0.438 & 0.913 \\
\hline
\end{tabular}

Harman's one-factor test was also performed to determine the existence of commonmethod bias (Podsakoff et al., 2003). Results indicate that the largest common variance explained by a single factor was $25.03 \%$, far below the advocated threshold of $50 \%$ of total variance explained. We can thus eliminate common method bias as a threat to our study.

\subsection{Calibration}

Data calibration is necessary when employing fsQCA and was carried out via $R$ software. The raw data collected from our survey questionnaire was converted into fuzzy set values before analysis (Ragin, 2000). Following the procedure outlined by Ragin (2008a, $2008 \mathrm{~b}$ ), the original scores of the variables in our research model were calibrated to fuzzy membership scores (ranging from 0 to 1 ) by utilizing the calibrating function accessible from 
the fsQCA 2.5 software.

Three qualitative breakpoints $(1,0.4$, and 0$)$ were designated to calibrate predictor variables (i.e., perceived enjoyment, social interaction, information documentation, information sharing, media appeal and continuance intention) into fuzzy sets. To match the fuzzy set calibration with the seven-point Likert scale employed for data collection, we set the original values of 7, 4 and 1 to correspond respectively to the three anchors. A full membership value of 1 was assigned to responses with an answer of 7, 0.4 was assigned to a response of 4, and 0 was assigned to an answer of 1 . The other values of variables (such as 2 , 3 , 5, and 6) were calibrated based on the linear function fit into the four values of the variables.

Membership values for other variables (e.g., gender) were also assigned based on the abovementioned sub-linear method. When transforming gender, as a binary variable, into fuzzy set, a male was assigned a low membership (0), whereas a female was coded with full membership (1). Frequency of use (FRE) is a dichotomous condition that measures the number of times WeChat is used during a day and it is coded in the following way: less than one time a day $=0$, just one time a day $=0.05$, several times a day $=0.5$, and many times a day $=1$. After specifying the breakpoints for set membership, each variable was calibrated.

\subsection{Qualitative Comparative Analysis}

For data analysis, we operate on the postulation that the presence of information documentation, information sharing, media appeal, perceived enjoyment, and social interaction, should be associated with the presence of our targeted outcome of interest: continuance intention towards social media, while gender and frequency of use would be related to continuance intention to use social media regardless of their presence or absence. That is, users' continuance intention should not be dictated by whether they are males or females, or how frequently WeChat has been used during a day.

After calibrating the variables, a truth table was constructed to perform qualitative comparative analysis. A truth table encompasses all logically plausible combinations of casual conditions are included. Because there are seven causal conditions (perceived enjoyment, social interaction, information documentation, information sharing, media appeal, gender and use frequency) in our research model, the truth table consists of $128\left(2^{\wedge} 7\right)$ distinct combinations or configurations. As the sample cases in a study might be limited and may not necessarily meet all possible configurations in the truth table, the initial truth table must be finetuned to isolate relevant configurations by setting a number-of-cases (frequency) threshold (Ragin, 2009). In this study, we opted for a frequency threshold of three cases. After finetuning the truth table, the analysis moved to the identification of distinct configurations. 
Table 5 depicts the configurations that culminate in a high membership score regarding users' continuance intention towards WeChat. These configurations entail both intermediate and complex solutions. The consistency and coverage (raw coverage and solution coverage) are also reported in Table 5. Consistency measures the extent to which configurations are sufficient for an outcome of interest to emerge (Ragin, 2008b). Solution coverage and raw coverage measure the degree to which the configurations can describe the outcome of interest (Ragin, 2008b). As articulated by Ragin (2008a), the consistency value aids in determining the fit of each configuration. If a configuration exceeds the predefined consistency threshold of 0.75 , the causal conditions it embodies are deemed to be sufficient in generating the outcome. Conversely, configurations with consistency values below the threshold value of 0.75 are regarded as being insufficient. In this study we set the consistency threshold at 0.90 to ensure a high membership value for the configurations. As shown in Table 5, the raw coverage values are between 0.157 and 0.690 and the solution coverage value is 0.746 . All consistency values exceed the cut-off value of 0.90 . The configurations of continuance intention, as exhibited in the solution table (see Table 5), satisfy the required threshold (Ragin, 2008a), thereby indicating all configurations are sufficient in yielding the outcome of interest (Rihoux \& Ragin, 2009). Furthermore, as shown in Table 5, the solution consistency is 0.974, and the model explains $74.6 \%$ of the cases of continuance intention towards WeChat.

Table 5. Complex Solutions of fsQCA Method

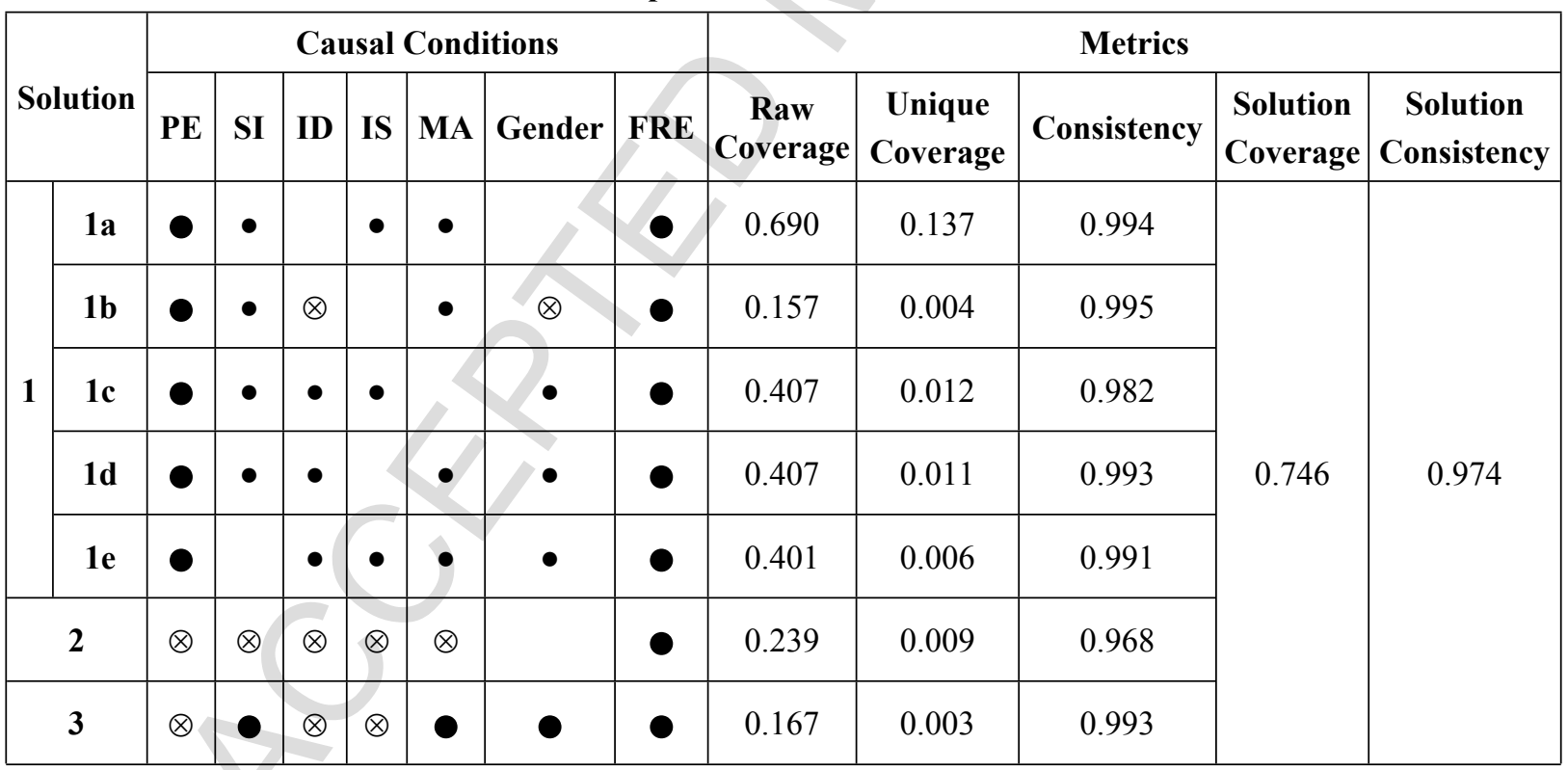

: Presence of casual conditions; $\otimes$ : Absence or negation of casual conditions; and blank cells indicate 'Don't care' conditions. Large circles refer to core conditions, and small circles reflect peripheral conditions.

Based on the equifinality of different core conditions, both first- and second-order solutions exist in configurations (Fiss 2011). In this study, we further identified three firstorder equifinality of solutions as well as a second-order, within-type equifinality of solution for configuration 1 (i.e., 1a, 1b, 1c, 1d and 1e) (see Table 5). The fuzzy membership scores of 
the seven complex solutions on the outcome of interest (i.e., continuance intention) are depicted in Figure 1. As shown in Figure 1, the relationships between continuance intention and the various configurations of causal conditions are asymmetrical. Moreover, all cases are above the diagonal, thereby lending support to the sufficiency of the derived configurations. From the analytical results, we can thus infer that fsQCA is appropriate for offering a holistic picture of the causal conditions driving users' continuance intention towards social media.

Figure 1. Analytical Results

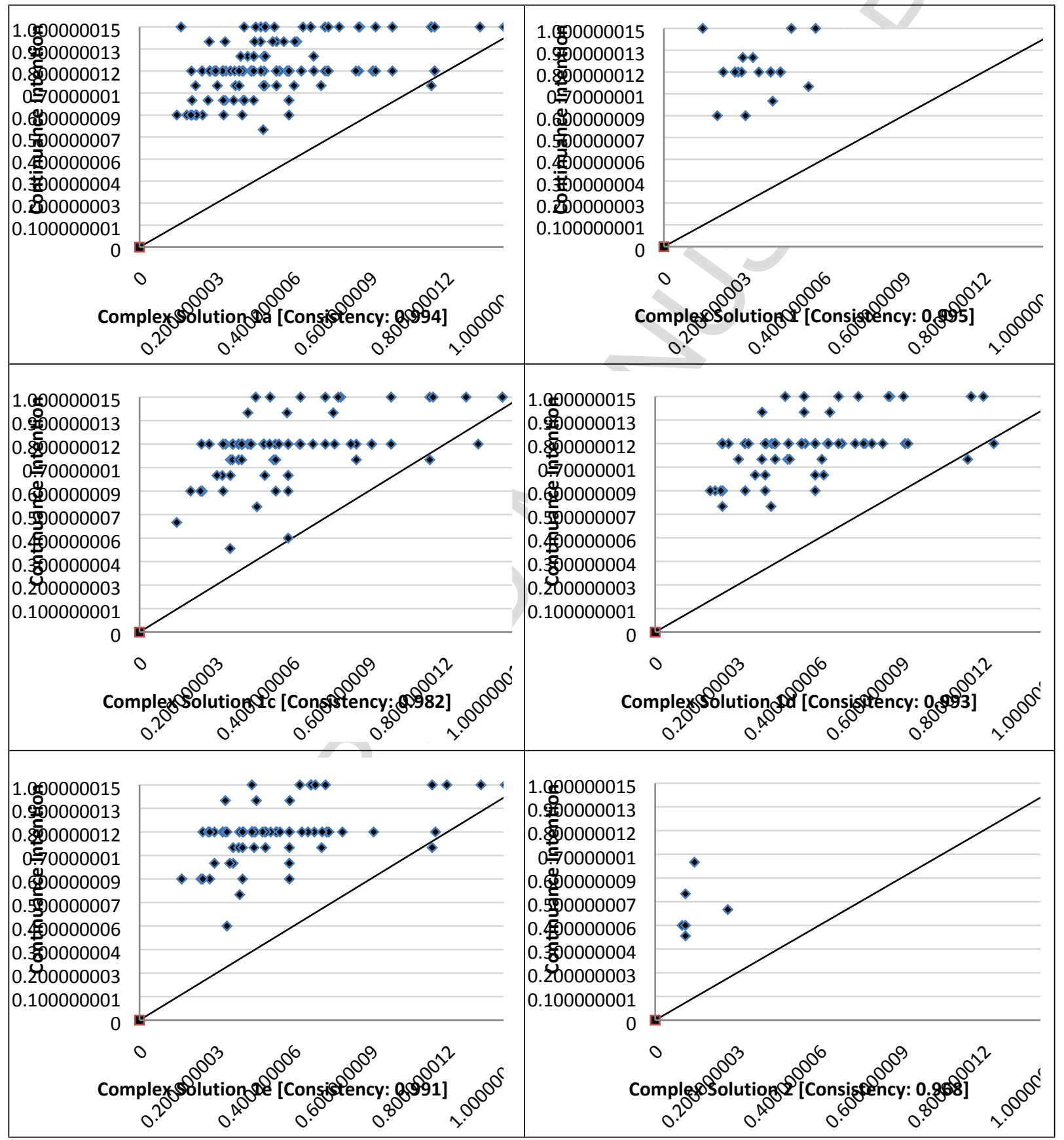




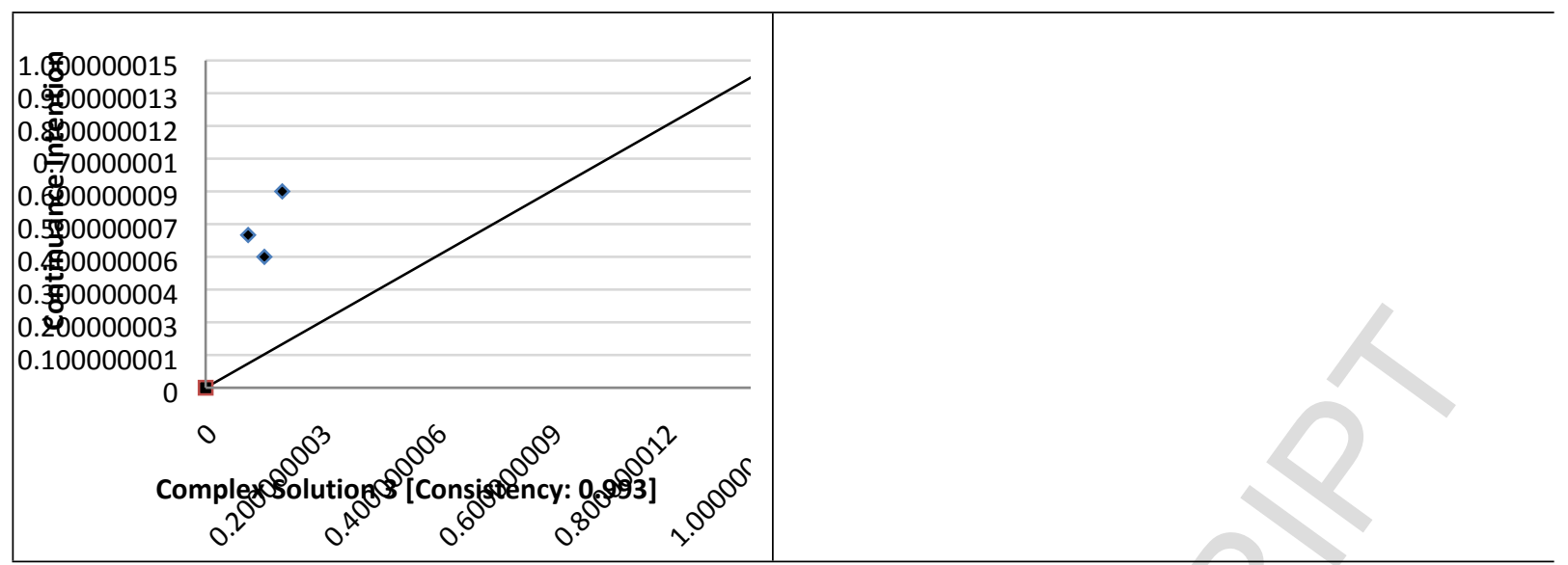

\section{DISCUSSION AND CONCLUSIONS}

Results indicate that there are three major configurations of causal conditions that underpin users' continuance intention towards WeChat. As shown in Table 5, the pattern of core, peripheral, and neutral conditions varies across the three configurations.

Solution 1 holds that the perceived enjoyment and frequency of WeChat use are joint members of the set of continuance intention, implying that perceived enjoyment and frequency of WeChat use constitute core conditions for continued usage of WeChat. Within extant literature, past studies have certified that frequency of social media use is an important factor leading to users' continuance intention (Hsiao, Chang, \& Tang, 2016; Hu, Stafford, Kettinger, Zhang, \& Dai, 2017). But at the same time, frequent usage of social media is not sufficient in driving continuance intention. Perceived enjoyment should be present together with other peripheral factors. In other words, our finding indicates that social media users should not only use social media frequently, but they should also feel the fun and happiness in using social media. If they also perceive the social interaction, information documentation, information sharing, and/or media appealing in social media use, they intend to continue using social media. Otherwise, they are less inclined to continue using social media despite its appeal as a communication channel.

Furthermore, as shown in Table 1, the first solution embodies five configurations (1a, $1 \mathrm{~b}, 1 \mathrm{c}, 1 \mathrm{~d}, 1 \mathrm{e})$ of casual conditions, showing the major features of the five different subgroups of users. Specifically, Solution 1a indicates that frequency, in combination with enjoyment, is a sufficient condition for both male and female users to continue using WeChat if they also possess positive perceptions about the information sharing capabilities, media appeal and social interaction afforded by WeChat. For male users, frequency, in combination with enjoyment, is a sufficient condition if they possess positive perceptions about the media appeal and social interaction afforded by WeChat, albeit with negative perceptions about its information documentation capabilities (Solution 1b). For female users, frequency, in combination with enjoyment, is sufficient in predicting continuance intention whenever they 
possess positive perceptions about: (1) information documentation and sharing capabilities and social interaction (Solution 1c); (2) information documentation capabilities and media appeal (Solution 1d); as well as (3) information documentation and sharing capabilities and media appeal (Solution 1e) afforded by WeChat.

Conversely, Solution 2 reveals that the frequency of WeChat usage plays an instrumental role in both male and female users' continuance intention in spite of the absence of enjoyment, information documentation, information sharing, media appeal, and social interaction. This implies that users, who use social media very often, are likely to persist even when they have no or negative perceptions on enjoyment, social interaction, information documentation, information sharing and media appeal in social media use. In other words, frequent social media usage could lead to the formation of habitual behaviors among users.

As shown in Solution 3, for female users, frequency of WeChat usage, in combination with media appeal and social interaction, are sufficient for securing users' continuance intention towards WeChat even when users possess negative perceptions about enjoyment, as well as information documentation and sharing capabilities afforded by WeChat. This implies that female users have the intention to continue using WeChat if they use it frequently enough and deem WeChat to be an attractive medium for communication and social interaction. In all identified solutions, the frequency of WeChat use appears as a core condition.

As shown in Table 5, Solution 1 includes 5 configurations, covering the membership values of the observations from $15.7 \%$ to $69.0 \%$, whereas Solution 2 covers $23.9 \%$ of the membership values, and Solution 3 covers $16.7 \%$ of the membership values. All three solutions represent sufficient configurations of causal conditions for continuance intention and Solution 1 is the most prevalent configuration for predicting users' continuance intention towards WeChat.

\subsection{Implications for Theory and Practice}

The study contributes to IS research on several fronts. First, this study contributes to extant literature on continued usage of social media by deriving distinct configurations of causal conditions that culminate in continuance intention from a configuration standpoint. This enriches previous work that is concentrated primarily on exploring the net effect exerted by discrete factors on continuance intention. Second, the study expands on the research stream on IS user behavior by offering empirical evidence that attests to the applicability of a configurational lens in deciphering users' continuance intention towards social media.

Our findings can also be harnessed by practitioners. By deriving multiple configurations of causal conditions for realizing the outcome of continuance intention, our study illustrates that the presence of a single condition, by itself, cannot guarantee users' continued usage of social media, and that a combination of factors must be taken into account. 
Consequently, social media service providers could concurrently pursue a series of differentiated strategies to retain users on their platforms.

For instance, social media service providers can increase the frequency with which users utilize social media by offering bonuses for logging into social media daily or investing in functionality upgrades. This is because the provision of value-added features on a social media platform is likely to entice users to utilize the platform much more frequently, which in turn could develop into a habit.

Additionally, enhancing social interaction features and improving the attractiveness or appeal of social media will help to retain female users who utilize social media frequently. This is because our findings indicate that female users are likely to turn to social media for communication and peer interaction in their daily lives.

Finally, improving the hedonic function of social media can be another strategy for retaining users by inducing perceptions of enjoyment. Nonetheless, this strategy only works on female users who use social media frequently and possess positive perceptions about either (1) information documentation and sharing capabilities and social interaction; (2) information documentation capabilities and media appeal, or; (3) information documentation and sharing capabilities and media appeal afforded by social media. This strategy will also aid in retaining male users if they have positive perceptions about information sharing capabilities and social interaction afforded by social media. The aforementioned peripheral conditions should be taken into consideration to trigger the main effect of enjoyment.

\subsection{Limitations and Future Research Directions}

This paper has a couple of caveats that could be addressed in future research. First, this study was conducted in the context of social media whereby the motivations for continued usage and the nature of technological innovation could differ. In this regard, findings from this study may not be generalizable to other technological contexts. Future research should therefore compare and contrast the antecedents of IS continuance, as derived in this study, against those identified in other contexts. Second, this study was conducted among Chinese social media users. Future research could consider replicating our study across other countries or cultural backgrounds.

\section{REFERENCES}

1. Al-Debei, M. M., Al-Lozi, E., \& Papazafeiropoulou, A. (2013). Why people keep coming back to Facebook: Explaining and predicting continuance participation from an extended theory of planned behavior perspective. Decision Support Systems, 55(1), 43 e54.

2. D. Berg-Schlosser, G. De Meur, B. Rihous, C.C. Ragin. (2009) Qualitative comparative analysis (QCA) as an approach. B. Rihoux, C.C. Ragin (Eds.), Configurational comparative methods: Qualitative comparative analysis (QCA) and related techniques (applied social research methods), Sage, Thousand Oaks and London (2009), pp. 1-18

3. Bhattacherjee, A. (2001). Understanding information systems continuance: An expectation 
confirmation model. Mis Quarterly, 25(3), 351-370.

4. Cheng, C-F, Chang, M-L, Li, C-S. (2013) Configuration paths to successful product innovation. Journal of Business Research. 2013(66), 2561-2573

5. Chin, W. W. (1998). The partial least squares approach for structural equation modeling Modern methods for business research (pp. 295-336). Mahwah, NJ, US: Lawrence Erlbaum Associates Publishers.

6. Csikszentmihalyi, M., \& LeFevre, J. (1989). Optimal experience in work and leisure. Journal of Personality and Social Psychology, 56(5), 815-822. doi: 10.1037/0022-3514.56.5.815

7. Davis, F. (1989) Perceived usefulness, perceived ease of use, and user acceptance of information technology. MIS Quarterly, 13, 319-340.

8. DeLone, W. H., \& McLean, E. R. (1992). Information Systems Success: The Quest for the Dependent Variable. Information Systems Research, 3(1), 60-95. doi: doi:10.1287/isre.3.1.60

9. Fishbein, M. \& Ajzen, I. (1975) Belief, attitude, intention, and behavior: an introduction to theory and research. Addison-Wesley, MA.

10. Fiss, P. (2011). Building better causal theories: a fuzzy set approach to typologies in organization research. Academy of Management Journal, 54(2), 393-420.

11. Fornell, C., \& Larcker, D. F. (1981). Structural Equation Models With Unobservable Variables and Measurement Error: Algebra and Statistics. Journal of Marketing Research (JMR), 18(3), 382-388.

12. Gallego, M. D., Bueno, S., \& Noyes, J. (2016). Second Life adoption in education: A motivational model based on Uses and Gratifications theory. Computers \& Education, 100, 81-93. doi: 10.1016/j.compedu.2016.05.001

13. Hsu, M. H., Tien, S. W., Lin, H. C., \& Chang, C. M. (2015). Understanding the roles of cultural differences and socio-economic status in social media continuance intention. Information Technology \& People, 28(1), 224-241. doi: 10.1108/itp-01-2014-0007

14. James, M. L., Wotring, C. E., \& Forrest, E. J. (1995). An exploratory study of the perceived benefits of electronic bulletin board use and the impact on other communication activities. Journal of Broadcasting \& Electronic Media, 39(1), 30-50.

15. Katz, E., Blumler, J. G., \& Gurevitch, M. (1974). Utilization of Mass Communication by the Individual. In J. G. Blumler \& E. Katz (Eds.), The Uses of Mass Communications: Current Perspectives on Gratifications Research (pp. 19-32). Thousand Oaks, London, New Delhi: SAGE Publications.

16. Lee, E-J \& Kim, Y-W. (2014) How social is Twitter use? Affiliative tendency and communication competence as preditors. Computers in Human Behavior 2014 (39), 296-305.

17. Lee, Maria R., David C. Yen, C.Y. Hsiao (2014) Understanding the perceived community value of Facebook users. Computers in Human Behavior 2014 (35), 350-358.

18. Li, H., Liu, Y., Xu, X., Heikkilä, J., \& van der Heijden, H. (2015). Modeling hedonic is continuance through the uses and gratifications theory: An empirical study in online games. Computers in Human Behavior, 48, 261-272. doi: http://dx.doi.org/10.1016/j.chb.2015.01.053

19. Lin, K., \& Lu, H. (2011). Why people use social networking sites: An empirical study integrating network externalities and motivation theory. Computers in Human Behavior, 27(3).

20. Liu, C. C., \& Chang, I. C. (2016). Model of online game addiction: The role of computermediated communication motives. Telematics and Informatics, 33(4), 904-915.

21. Liu, I. L. B., Cheung, C. M. K., \& Lee, M. K. O. (2016). User satisfaction with microblogging: Information dissemination versus social networking. Journal of the Association for Information Science and Technology, 67(1), 56-70.

22. Liu, Y., Mezei, J., Kostakos, V., and Li, H. (2017). Applying configurational analysis to is behavioural research: a methodological alternative for modelling combinatorial 
complexities. Information Systems Journal, 91(11), 139-144.

23. Ng, M. (2016) Factors influencing the consumer adoption of Facebook: A two-country study of youth markets. Computers in Human Behavior, 2016 (54). 491-500.

24. Papacharissi, Z. (2002). The Self Online: The Utility of Personal Home Pages. Journal of Broadcasting \& Electronic Media, 46(3), 346-368.

25. Park, M., \& Park, J. (2009). Exploring the influences of perceived interactivity on consumers'e-shopping effectiveness. Journal of Customer Behaviour, 8(4),

26. Park, Y. \& El Sawy, O.A. (2012). Discovering the multiface- ted roles of information technologies with a holistic con- figurational theory approach. 2012 45th Hawaii International Conference on System Sciences, pp.5204-5212.

27. PewResearch. (2015). Social Media Update 2014. Pew Research Center, 2015.

28. Podsakoff, P. M., \& Organ, D. W. (1986). Self-Reports in Organizational Research: Problems and Prospects. Journal of Management, 12(4), 531.

29. Ragin, C.C. (1987) In: The Comparative Method: Moving Beyond Qualitative and Quantitative Strategies, Ragin, C.C. (ed). University of California Press, Berkeley.

30. Ragin, C. C. (2000). Fuzzy-set social science. Chicago: University of Chicago Press.

31. Ragin, C. C. (2008a) Redesigning Social Inquiry: Fuzzy Sets and Beyond. Chicago: University of Chicago Press, Chicago.

32. Ragin, C. C. (2008b). User's guide to fuzzy-set/qualitative comparative analysis, Available at: http://www.u.arizona.edu/ cragin/fsQCA/download/fsQCAManu al. pdf.

33. Rihoux, B. \& Ragin, C.C. (2009). In: Configurational comparative methods: Qualitative comparative analysis (QCA) and related techniques, Rihoux B. \& Ragin C. C. (eds.). Thousand Oaks and London, Sage.

34. Sharma, S., Joshi, A, Sharma, H. (2016) A multi-analytical approach to predict the Facebook usage in higher education. Computers in Human Behavior 2016 (55, part A), 340-353.

35. Tecent. (2016b). Report on WeChat. Retrieved 2016-03-21, from http://mp.weixin.qq.com/s?_biz=MzA5NDMxMTAyMg $==\&$ mid $=402733938 \& i d x=1 \&$ sn $=d$ e14d96ecbde2ac6be9a99c8a4a3b6bf\&scene=5\&srcid=0909GW3fjWRU4TizgUXXaI8b\#rd

36. van der Heijden, H. (2003). Factors influencing the usage of websites: the case of a generic portal in The Netherlands. Information \& Management, 40(6), 541-549. doi:

37. Venkatesh, V., Morris, M.G., Davis, G.G. \& Davis, F.D. (2003) User acceptance of information technology: toward a unified view. MIS Quarterly, 27, 425-478.

38. Woodside, A.G. (2013) Moving beyond multiple regression analysis to algorithms: calling for adoption of a paradigm shift from symmetric to asymmetric thinking in data anal- ysis and crafting theory. Journal of Business Research, 66, 463-472.

39. Zeithaml, V. A. (1988). Consumer perceptions of price, quality, and value: A means-nd model and synthesis of evidence. Journal of Marketing, 52(3), ....

40. Zhang, C-B, Li, Y-N, Wu, B. \& Li, D-J. (2017). How WeChat can retain users: Roles of network externalities, social interaction ties, and perceived values in building coninuance intention. Computers in Human Behaviors, 2017 (69), 284-293. 


\section{APPENDIX. SUMMARY OF MEASUREMENT ITEMS}

Perceived Enjoyment (PE) (van der Heijden, 2003)

PE1: I find using WeChat to be enjoyable.

PE2: The actual process of using WeChat is pleasant.

PE3: I have fun using WeChat.

Social Interaction (SI) (Liu et al., 2016; Papacharissi, 2002)

SI1: Using WeChat enables me to maintain a daily, personal connection with friends and family

SI2: Using WeChat enables me to connect with friends in my real life

SI3: Using WeChat enables me to keep in touch with friends in my real life

Information Documentation (ID) (Liu et al., 2016)

ID1: I use WeChat to keep a record of what I learn. (Deleted)

ID2: I use WeChat to keep track of what I am doing.

ID3: I use WeChat to document my life.

Information Sharing (IS) (Liu et al., 2016)

IS1: I use WeChat to provide information.

IS2: I use WeChat to share information that is useful to other people.

IS3: I use WeChat to present information on my interests.

Media Appeal (MA) (Liu et al., 2016)

MA1: I like WeChat where I can communicate with others immediately.

MA2: WeChat is the easiest, most cost-effective way for communication.

MA3: WeChat is easier for me to maintain.

Continuance Intention (CI) (Bhattacherjee, 2001)

CI1: I intend to continue using WeChat rather than discontinue its use.

CI2: My intentions are to continue using WeChat than use any alternative means.

CI3: I would like to continue my use of WeChat. 


\section{Acknowledgement}

This research has been partially supported by the grant from the National Natural Science Foundation of China (project No. 71403301). 


\section{Highlight}

The relationships between the motivators and IS user behavior might be asymmetric.

Seven different configurations bring the same outcome of continuance intention.

Use frequency and perceived enjoyment are the core conditions.

Different strategies should be taken to retain social media customer. 